\title{
Proteomic and lipidomic analysis of exosomes derived from ovarian cancer cells and ovarian surface epithelial cells
}

\author{
Lin Cheng ${ }^{1}$, Kun Zhang ${ }^{1}$, Yunan Qing ${ }^{1}$, Dong Li ${ }^{1}$, Manhua Cui ${ }^{1}$ Peng Jin² and Tianmin Xu ${ }^{1 *}$ (D)
}

\begin{abstract}
Background: The limitation of current biomarker of early stage ovarian cancer and the anatomical location of ovarian (depths of the pelvic) make ovarian cancer difficult to be detected in early stage. Growing evidence shows exosomes as key information transmitters, it carried molecules, such as miRNAs, proteins, lipids, double-stranded DNA have been reported as promising biomarkers in many diseases. However, little is known about the protein and lipid composition of ovarian cancer.
\end{abstract}

Methods: Here, we report proteomic and lipidomic analysis of exosomes derived from ovarian cancer cells (SKOV3) and ovarian surface epithelial cells (HOSEPiC).

Results: A total of 1433 proteins and 1227 lipid species were identified from two cell line derived exosomes. Several lipid species and proteins significantly differ in SKOV-3 derived exosomes compared to those from HOSEPiC. For example, we noted that ChE and ZyE species were in general more abundant in exosomes from SKOV-3 than from HOSEPiC; Collagen type $V$ alpha 2 chain (COL5A2) and lipoprotein lipase (LPL) were significantly higher in SKOV-3 derived exosomes than HOSEpic $(p<0.05)$.

Conclusions: Our research indicates the promising role of exosomal proteins and lipids in the early diagnosis of ovarian cancer.

Keywords: Ovarian cancer, Exosome, Proteomics, Lipidomics

\section{Background}

Exosomes are small $(30-150 \mathrm{~nm}$ diameter) doublemembrane bound vesicles that contain several molecules that are specific to the parent cells [1-3]. The mechanism of exosome biogenesis and cargo selection are still unclear, but there are several studies provided precise clues [4-8]. All cells release exosomes either constitutively or upon activation/stress, and tumor cells are released in larger quantity in compared to normal cells [9, 10]. As an information transmitter, exosomes exchange information with distant cells via carrying complex packets stuffed with a selection of proteins, lipids, and nucleic acids. Moreover, exosomes have been shown to play a role in immune response, antigen presentation,

\footnotetext{
* Correspondence: xutianmin@126.com

${ }^{1}$ The Second Hospital of Jilin University, 218 Ziqiang Street, Changchun 130000 , China

Full list of author information is available at the end of the article
}

cell migration, cell differentiation, tumor invasion and other aspects [11]. During the development of cancer, exosomes released from cancer cells are able to transfer a variety of molecules, including those that are cancerspecific, to other cells so as to manipulate their environment, making it more favorable for tumor growth and invasion [11, 12]. Recent studies implicate that exosomes can mediate drug resistance in various intracellular processes [13].

Since exosomes have been explored from a variety of bodily fluids, including urine [14], saliva [15], blood [9] and cerebrospinal fluid [16], milk [17], and the double-membrane structure provide a shelter to multiple bioactive molecule which avoids degradation. Thus, exosomes seem as a vehicle that is full of ideal non-invasive biomarkers with great potential in the detection of oncogenesis, tumor spread, and drug resistance. However, data attributing to cancer specific intercellular transfer molecules to exosomes are still limited. The 
structure and function of membranes and domains are determined by the assembled molecular lipids and membranebound proteins. In-depth characterization of exosomes will help to elucidate their precise biological functions.

Ovarian cancer $(\mathrm{OC})$ is the most fatal gynecologic malignancy worldwide $[18,19]$. Because of the lack of early diagnostic markers [20], almost $50 \%$ of OC is diagnosed in women over the age of 65 [21], the majority of ovarian cancer patients are diagnosed in an advanced stage [22]. Hence, to address this question, we performed a comparative analysis of the protein and lipid composition of 2 different cell line derived exosomes. We chose an ovarian cancer (SKOV-3) and an ovarian surface epithelial (HOSEPiC) cell line because $70 \%$ ovarian cancer origin of ovarian germinal epithelium. Our results reveal enriched proteins and pathways, potentially involved in intercellular communication, and an extraordinary sorting of lipids into exosomes which may dependent on its original.

\section{Materials and methods Cell culture}

An human ovarian surface epithelial cell line (HOSEPiC) and an ovarian cancer cell SKOV-3 were cultured in $37^{\circ} \mathrm{C}$ in $5 \%$ carbon dioxide and RMPI-1640 medium supplemented with 10 and 15\%, EV-depleted fetal bovine serum (FBS was centrifuged overnight at $120,000 \mathrm{~g}$ to pellet out vesicles), $100 \mathrm{units} / \mathrm{ml}$ penicillin and $100 \mu \mathrm{g} /$ $\mathrm{ml}$ streptomycin.

\section{Exosome isolation}

Cells were incubated with EV-depleted medium for 2 days to reach approximately $80 \%$ confluency and supernatants were collected for exosomes isolation using classical differential ultracentrifugation methods [23] with tiny modification. Briefly, the supernatant was centrifuged to remove dead cells, cell debris and microvesicles at $300 \mathrm{~g}$ for $10 \mathrm{~min}, 2000 \mathrm{~g}$ for $10 \mathrm{~min}$ and $10,000 \mathrm{~g}$ for $30 \mathrm{~min}$. The supernatant was concentrated using a 100 KDa molecular weight cut-off centrifugal filter (Millipore, Germany). The concentrated suspension was centrifuged in a SW41 ultracentrifuge rotor at $110,000 \mathrm{~g}$ for $80 \mathrm{~min}$. In order to avoid missing exosomes, approximately $2 \mathrm{ml}$ of supernatant was left. These volumes were mixed and exosomes were pelleted in a SW41 rotor at $110,000 \mathrm{~g}$ for $80 \mathrm{~min}$. The supernatant was gently removed and the exosome pellet was washed with $11 \mathrm{~mL}$ PBS solution. Exosomes was pelleted again by a third round of ultracentrifugation was with the same parameters. Exosomes used for proteomic analysis were resuspended in $30 \mathrm{ul}$ of SDT buffer (4\% SDS, $100 \mathrm{mM}$ DTT, $150 \mathrm{mM}$ Tris- $\mathrm{HCl} \mathrm{pH} 8.0$ ). Exosomes used for flow cytometry analysis (FACS), TEM and size analysis were resuspended in PBS. Exosomes used for lipidomic were resuspended in $200 \mathrm{ul}$ of pure water.

\section{Transmission electron microscopy}

Pelleted exosomes were resuspended in PBS. 5ul resuspended exosomes were loaded onto 150 mesh copper grids and stood at RT for $5 \mathrm{~min}$. Excess liquid was removed using filter paper. The exosome containing grids were air-dried and 5ul 2\% phosphotungstic acid was used to stained exosomes at RT for $5 \mathrm{~min}$. Excess liquid was removed using filter paper again and the stained exosome containing grids were air-dried and observed under the electron microscope at $80 \mathrm{kV}$.

\section{Flow cytometry analysis}

As previously described with tiny modification, exosomes were attached to $4 \mathrm{um}$ aldehyde/sulphate latex beads (Invitrogen) by mixing $30 \mu \mathrm{g}$ exosomes in a $10 \mathrm{ul}$ volume of beads in a $1.5 \mathrm{ml}$ microcentrifuge for $15 \mathrm{~min}$ at room temperature. This suspension was diluted to 1 $\mathrm{ml}$ with PBS and incubated on a tube rotator overnight at $4{ }^{\circ} \mathrm{C}$. The free binding sites were saturated by adding $110 \mathrm{ul}$ of $1 \mathrm{M}$ glycine and left stood on the branch at room temperature for $30 \mathrm{~min}$. Exosomes-bound beads were washed three times in $0.5 \%$ BSA in PBS and centrifuged for $4 \mathrm{~min}$ at $4000 \mathrm{~g}$. The bead pellet was responded in $0.5 \mathrm{ml} 0.5 \%$ BSA in PBS. 10ul coated bead were incubated with $5 \mathrm{ul}$ anti-Human CD63 and CD9 (12-0639, eBioscience, 11-0098-42, Invitrogen) antibody diluted with $45 \mathrm{ul} 0.5 \%$ BSA in PBS $30 \mathrm{~min}$ at $4{ }^{\circ} \mathrm{C}$. For each measurement a total number of 10,000 events were recorded.

\section{Size analysis of exosomes}

Pelleted exosomes were resuspended in PBS and analyzed using NANO ZS 90 (NanoSight, Malvern, UK) according to the manufacture.

\section{Western blot}

All cells were harvested upon completion of 2 days in EVdepleted medium. The cell pellets were washed twice with ice-cold PBS and lysed immediately with the lysis buffer (Protein Extraction Mammalian Total Protein Extraction Kit, Transgen Biotech) maintained at $4{ }^{\circ} \mathrm{C}$ for $30 \mathrm{~min}$. Cellular debris was removed by centrifugation $(14,000 \mathrm{~g}, 10 \mathrm{~min}$ at $4{ }^{\circ} \mathrm{C}$ ). Exosome suspensions were used for protein quantification directly, and protein amount was determined using a BCA protein assay kit (Beyotime Biotechnology). Denaturing SDS-Polyacrylamide gel electrophoresis was performed in $12 \%$ acrylamide gels using equivalent total protein. Separated proteins were transferred onto polyvinylidene difluoride membranes through electroblotting. Western blots were performed using primary and secondary antibodies coupled to HRP, diluted according to the suppliers' recommendations 
and detected using an enhanced chemiluminescence (ECL) system. The antibodies used were anti-FASN (ABclonal, A0462), anti-L1CAM (ABclonal, A8555), anti-TSG101 (Proteintech, 14,497-1-AP), anti-GAPDH (Proteintech, 60,0041-Ig), and anti- $\beta$-Actin (Proteintech, 60,008-1-Ig). All antibodies were raised in rabbit, except $\beta$-Actin and GAPDH that were raised in mouse.

\section{Proteomics}

3 replicate samples of exosomes from each source cell type were used for proteomic analysis. The detergent, DTT and other low-molecular-weight components in protein samples were removed using UA buffer $(8 \mathrm{M}$ Urea, $150 \mathrm{mM}$ Tris- $\mathrm{HCl} \mathrm{pH}$ 8.0) by repeated ultrafiltration (Microcon units, $10 \mathrm{kD}$ ). Then $100 \mu \mathrm{l}$ iodoacetamide (100 mM IAA in UA buffer) was added to block reduced cysteine residues and the samples were incubated for $30 \mathrm{~min}$ in darkness. The filters were washed with $100 \mu \mathrm{l}$ UA buffer three times and $100 \mu \mathrm{l} 25 \mathrm{mM}$ NH4HCO3 buffer twice. Finally, the protein suspensions were digested with $4 \mu \mathrm{g}$ trypsin (Promega) in $40 \mu \mathrm{l} 25$ $\mathrm{mM} \mathrm{NH} 4 \mathrm{HCO} 3$ buffer overnight at $37^{\circ} \mathrm{C}$, and the resulting peptides were collected as a filtrate. The peptides of each sample were desalted on C18 Cartridges (Empore $^{\mathrm{mm}}$ SPE Cartridges, Sigma), concentrated by vacuum centrifugation and reconstituted in $40 \mu \mathrm{l}$ of $0.1 \%$ $(\mathrm{v} / \mathrm{v})$ formic acid. The peptide content was estimated by UV light spectral density at $280 \mathrm{~nm}$ using an extinctions coefficient of 1.1 of $0.1 \%$ (g/l) solution that was calculated on the basis of the frequency of tryptophan and tyrosine in vertebrate proteins. The peptide mixture was loaded onto a reverse phase trap column (Thermo Scientific Acclaim PepMap100, $100 \mu \mathrm{m} * 2 \mathrm{~cm}$, nanoViper C18) connected to the C18-reversed phase analytical column (Thermo Scientific Easy Column, $10 \mathrm{~cm}$ long, $75 \mu \mathrm{m}$ inner diameter, $3 \mu \mathrm{m}$ resin) in buffer A (0.1\% Formic acid) and separated with a linear gradient of buffer B ( $84 \%$ acetonitrile and $0.1 \%$ Formic acid) at a flow rate of $300 \mathrm{nl} / \mathrm{min}$ controlled by IntelliFlow technology. MS analysis was performed on a Q-Exactive mass spectrometer (Thermo Scientific) that was coupled to Easy nLC (Thermo Scientific) for $120 \mathrm{~min}$.

\section{Lipidomics}

6 replicate samples of exosomes from each source cell type were used for lipidomic analysis. Exosome pellets were frozen at $-80^{\circ} \mathrm{C}$ and transferred to APT (Shanghai) on dry ice for lipid composition analysis. Samples thawed at $4{ }^{\circ} \mathrm{C}$ environment slowly, $200 \mathrm{ul}$ pure water and $240 \mathrm{ul}$ ice-cold methanol were added and vortex mixed. $800 \mathrm{ul} \mathrm{MTBE}$ were added and vortex mixed. The mixed solution was placed for $20 \mathrm{~min}$ at room temperature. Then the mixed solution was centrifuged at $8000 \mathrm{~g}$ for $15 \mathrm{~min}$ at $10{ }^{\circ} \mathrm{C}$. The upper organic phase was taken, and nitrogen was blown dry. The dried powder was re-resuspended in 200ul isopropyl before UPLCMS. The samples were separated by UHPLC Nexera lc30a system (Column temperature $45^{\circ} \mathrm{C}$, Flow rate at 300 $\mathrm{uL} / \mathrm{min}$, sample size $2 \mathrm{ul}$ ). Mobile phase composition A: $10 \mathrm{mM}$ ammonium formate acetonitrile aqueous solution (acetonitrile: Water $=6: 4, \mathrm{v} / \mathrm{v}$ ), B: $10 \mathrm{mM}$ ammonium formate acetonitrile isopropanol solution (acetonitrile: isopropanol =1:9, v/v). MS analysis was performed on a Q-Exactive mass spectrometer (Thermo Scientific). The mass spectrometer was operated in positive ion mode. MS data was acquired using a datadependent top 10 method dynamically choosing the most abundant precursor ions from the survey scan (300$1800 \mathrm{~m} / \mathrm{z}$ ) for HCD fragmentation.

\section{Analysis}

The proteomic MS data were analyzed using MaxQuant software version1.5.3.17 (Max Planck Institute of Biochemistry in Martinsried, Germany) [24] against the UniProt complete human proteome protein sequence database (version: 2018-01-15, number of sequences: 161,584.). Searches were performed with fragment ion mass tolerance of $20 \mathrm{ppm}$, maximum missed cleavage of 2 and carbamidomethylation of cysteine was specified as a fixed modification and oxidation of methionine as variable modification. Peptide False discovery $(\leqq 0.01)$ was set. Only protein groups identified with at least two or more peptides (sum of razor and unique) were carried forward in the analysis. Label-free quantification of proteins was performed via the LFQ method in Maxquant software. All statistical analyses were performed using $\mathrm{R}$ version 3.4. We also used gene ontology (GO) and KEGG pathway enrichment analyses to annotate biological function to proteins enriched in exosomes.

The lipidomic MS data were quantified using an LipidSearch software(Thermo Scientific $\left.{ }^{\mathrm{mm}}\right)$ for producing lipid identification and peak alignment (precursor tolerance: $5 \mathrm{ppm}$, product tolerance: $5 \mathrm{ppm}$, product ion threshold: $5 \%$ ). Data showed RSD $>30 \%$ were deleted. We selected the data which missing value were below $50 \%$ in the group to analyze using an SIMCA-P 14.1 software (Umetrics, Umea, Sweden). Quality control samples were used to monitor the overall quality of the lipid extraction and MS analyses. We also visualized the normalized protein and lipid profiles of exosomes on heatmaps.

\section{Results}

\section{Characterization of exosomes derived from two ovarian} cell lines

The exosomes secreted by SKOV-3 and HOSEPiC cells were isolated from EV-depleted medium by a combination of differential centrifugation. Exosomes obtained were extensively characterized using several methods 
such as western blot and flow cytometry analysis to identify specific exosomal markers, electron microscopy and NanoSight to identify specific exosomal structure and size (Fig. 1).

\section{In-depth proteomics of exosomes derived from two ovarian cell lines}

Using rigorous peptide and protein identification criteria total of 1433 proteins groups were identified from exosomes derived from SKOV-3 and HOSEPiC cells (732 proteins in SKOV-3 derived exosomes and 1242 proteins in HOSEPiC derived exosomes, Additional file 1: Table S1). 659 proteins were identified in the exosomes from both cell lines (Fig. 2a). Key to this project was the use of the nano-flow UPLC coupled to a Q-Exactive mass spectrometer. The quality deviations of all identified peptide segments were mainly distributed within $10 \mathrm{ppm}$, indicating that the identification results were accurate and reliable. We used Andromeda to analyze and grade MS spectrum showed in Fig. 2. Western blot signal intensities for exosome markers TSG101 were greater in the exosome fraction compared to the cell lysates. FASN and L1CAM was only verified in exosomes derived from HOSEPiC as identified by MS/MS. GAPDH, $\beta$-Actin and $\beta$-tubulin were not verified in exosomes by Westernblot although it was identified by MS/MS in both cell lines (Fig. 3).

Differentially expressed proteins and function analysis To further analyze this observation, we sub-screening differentially expressed proteins. Furthermore, only those
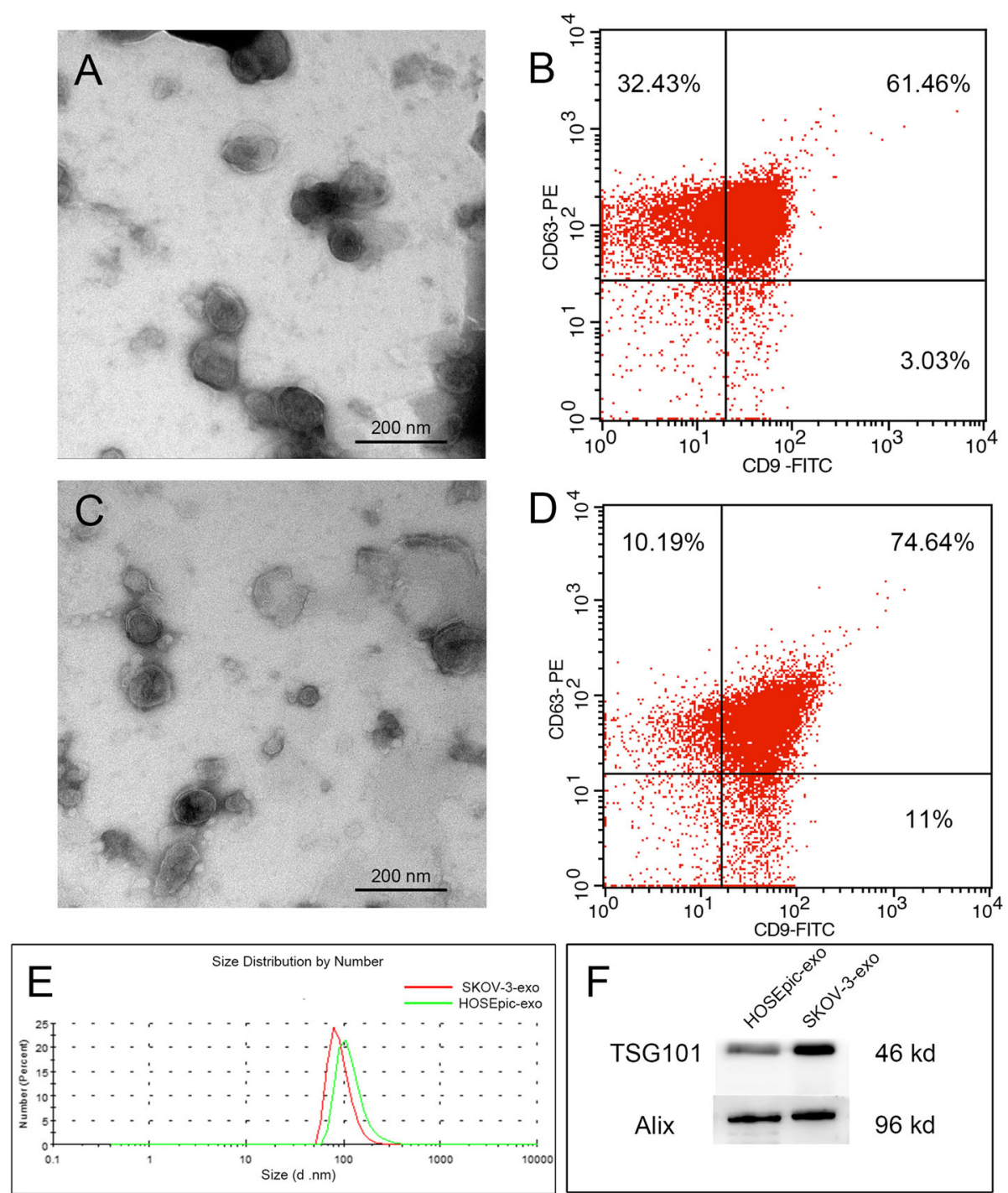

Fig. 1 Exosome isolation and analysis. A\&C Representative transmission electron microscopy (TEM) images obtained for exosomes from HOSEPiC and SKOV-3. Scale bar: $100 \mathrm{~nm}$. B\&D flow cytometry analysis analyses show intensities for exosomal markers (CD9, CD63). (E) Particle size distribution by NanoSight analysis of exosomes from HOSEPiC and SKOV-3 (F) Western blot analyses show increased intensities for exosomal markers (Alix, TSG101) 


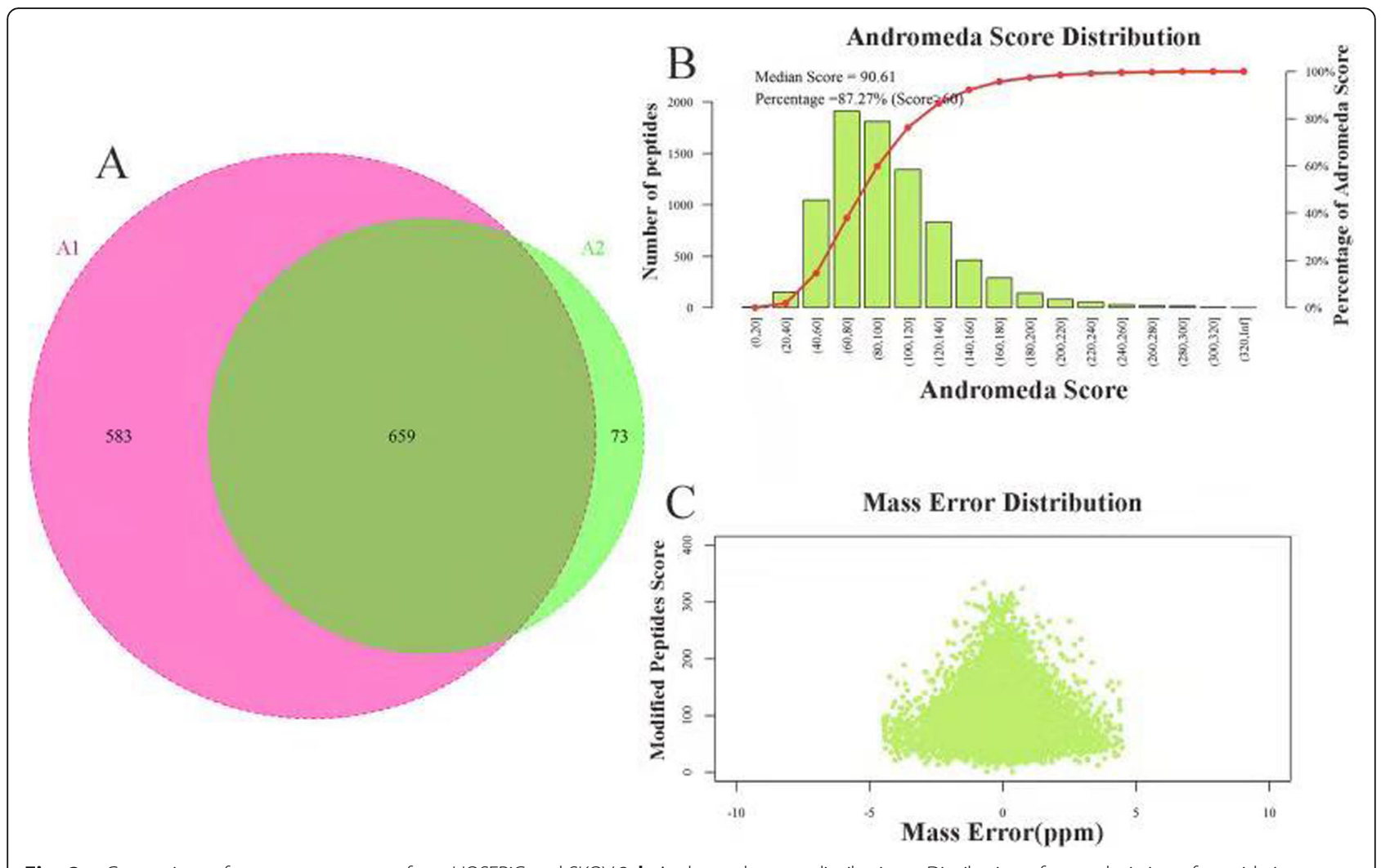

Fig. 2 a Comparison of exosome proteome from HOSEPiC and SKOV-3. b Andromeda score distribution c Distribution of mass deviation of peptide ions

proteins identified in 2 or more biological replicates in both cell line derived exosomes, with a $P$ value of less than 0.05 , and which fold change greater than 2.0 times (up more than 2 times or down less than 0.5 times were included in the profile differentially expressed in abundance. Those proteins identified in 2 or more biological replicates in only one cell line derived exosomes were included in consistent presence / absence expression profile (Fig. 4, Additional file 2: Table S2). To be pointed out, collagen type $\mathrm{V}$ alpha 2 chain (COL5A2) and lipoprotein lipase (LPL) were significant higher in SKOV-3 derived exosomes than HOSEpic $(p<$ $0.05)$. COL5A2 has been reported as specific predictive signature for the diagnosis and prognosis of pancreatic cancer [25] and bladder cancer [26].We also visualized the differentially expressed proteins on heatmaps and used gene ontology (GO) analysis (Blast2Go, https://www.blast2go.com/) to annotate biological function. Statistics showed the significant variation exosomal proteins derived from the two different cell lines involved in the following biological processes and molecular functions: transition metal ion transport, positive regulation of epithelial cell migration, carboxylic acid metabolic process, epithelial cell migration, transporter activity, transmembrane transporter activity, molecular transducer activity and receptor activity (Fig. 4). The FASTA protein sequences of differentially expressed proteins were blasted against the online Kyoto Encyclopedia of Genes and
Genomes (KEGG) database (http://geneontology.org/) to retrieve their KOs and were subsequently mapped to pathways in KEGG [27]. The corresponding KEGG pathways were extracted and showed in Fig. 4. In brief, pathways of cysteine and methionine metabolism and small cell lung cancer have shown significant differentially expressed.

\section{Lipidomic analysis showed high reproducibility}

To assess the reproducibility of our experiments, the samples of each group were mixed into quality control samples (QC) in equal quantity. The analysis results of the samples of QC UHPLC-obitrap MS base peak were compared for overlapping spectra, as shown in the Fig. 4, which shows that the response intensity and retention time of each chromatographic peak overlapped substantially, indicating that the experiment is relatively repetitive. PCA analysis was performed on all experimental samples and QC samples after pareto-scaling. As shown in Fig. 4, QC samples are closely clustered and located in the middle of each group, indicating that the lipidomic analysis showed high reproducibility.

\section{Characterization of lipid composition}

In order to identify lipid species differentially expressed in exosomes derived from SKOV-3 and HOSEPiC cells, 6 replicate samples of exosomes from each source cell type were analyzed. In total, 30 lipid classes, 1227 lipid 


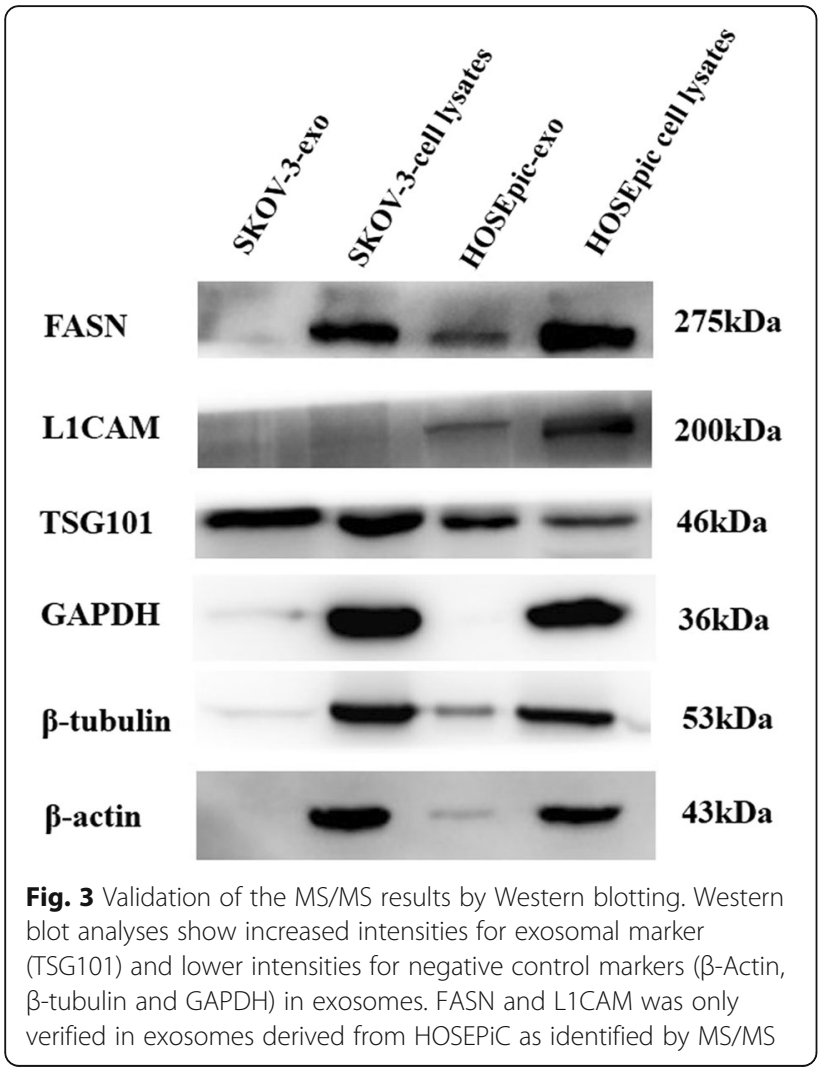

species were identified (Additional file 3: Table S3). In particular, SKOV-3 derived exosomes contained higher levels of GM3, ZyE, LPI, LPC, AcCa, LPS, LPG and ChE, lower levels of Cer, DGDG, PS, PI, PG, SM, PE, DG and CerG3 than exosomes derived from HOSEPiC cells $(p<$ $0.05)$, whereas more similar levels of other lipid classes were found (Additional file 4: Table S4). To be mentioned, no significant differences were found in TG, of which decreased levels were found to be a specific metabolic feature foreshadowing an early relapse in epithelial ovarian cancer (EOC) patients plasma lipidomics study [28].

\section{Important lipid alterations of two ovarian cell lines derived exosomes}

To further analyze lipidomic data, variable weight for the projection (VIP) was used to measure the impact strength and interpretation ability of each lipid expression pattern on the classification and discrimination of each group, and univariate statistical analysis was further performed to verify the significance of the difference in lipids. In this experiment, VIP $>1$ and $P$ value $<0.05$ was used as the screening standard, and the significant differences between each group was screened out and listed in Additional file 3: Table S3. In total, 110 lipid species were screened out as potential lipid biomarkers of EOC, which were presented in Fig. 5a and also listed in Table 1. To be interesting, some lipid species were reported by an early relapse biomarker in EOC [28], such as $\mathrm{LPC}(18: 0), \quad \mathrm{PC}(36: 3), \quad \mathrm{PC}(38: 6), \quad \mathrm{PC}(40: 5)$, $\mathrm{PC}(38: 6)$. We also used correlation analysis to help measure the degree of correlation between lipid molecules (Fig. 5c).

\section{Discussion}

Exosomal molecules, such as miRNA, protein, lipid, double-stranded DNA have been reported as promising biomarkers in pancreatic cancer [29], prostate cancer [14], pheochromocytoma [30], Stroke [31] and other diseases. Initially studies by Thomas [32] and Shen [33] had reported exosomal proteome profiles derived from different ovarian cancer cells in starvation conditions. In this article, we provide the in-depth proteomic and lipidomics analysis of exosomes derived from ovarian cancer cells and ovarian surface epithelial cells with EVdepleted medium and focus more on the metabolic perspective. As the venn diagram showed, high overlapped were found between two exosomal proteins. To obtain a systematic insight into the proteome profiles, we analyzed the significant differentially expressed proteins by GO and KEGG. The most enriched pathway were cysteine and methionine metabolism pathway. The content of various amino acid metabolic enzymes differentially expressed including L-lactate dehydrogenase, adenosylhomocysteinase, branched-chain-amino-acid aminotransferase, aspartate aminotransferase, and malate dehydrogenase. A proteomic profiling of plasma exosomes also found serine-type endopeptidase activity changed significantly in EOC patients [34], in the meantime, they found 10 genes (among the 50 differentially expressed genes) participated in the complement and coagulation cascade. However, we did not find any coagulation-related differentially expressed genes in our study. As the latest study demonstrated that neural stem/progenitor cell (NSC)-derived EVs function as independent metabolic units that are able to modify the concentrations of critical nutrients, with the potential to affect the physiology of their microenvironment [35], suggesting the low level of cysteine and methionine metabolic enzymes in tumor derived exosomes might be in favor of establishment of tumor microenvironment [12]. Lin et al. [36] observed that Glucose-6-phosphate dehydrogenase, transketolase and transaldolase 1, three key enzymes regulated pentose phosphate pathway, were all marked in the same exosomal parts of proteins between two late-stage ovarian cell lines, OVCA429 and HO8910PM. However, our data did not show these three key enzymes enrichment in SKOV-3 derived exosomes. But we observed that about $30 \%$ of differentially expressed proteins between 2 cell lines were participated in metabolic process. Interestingly, we also 


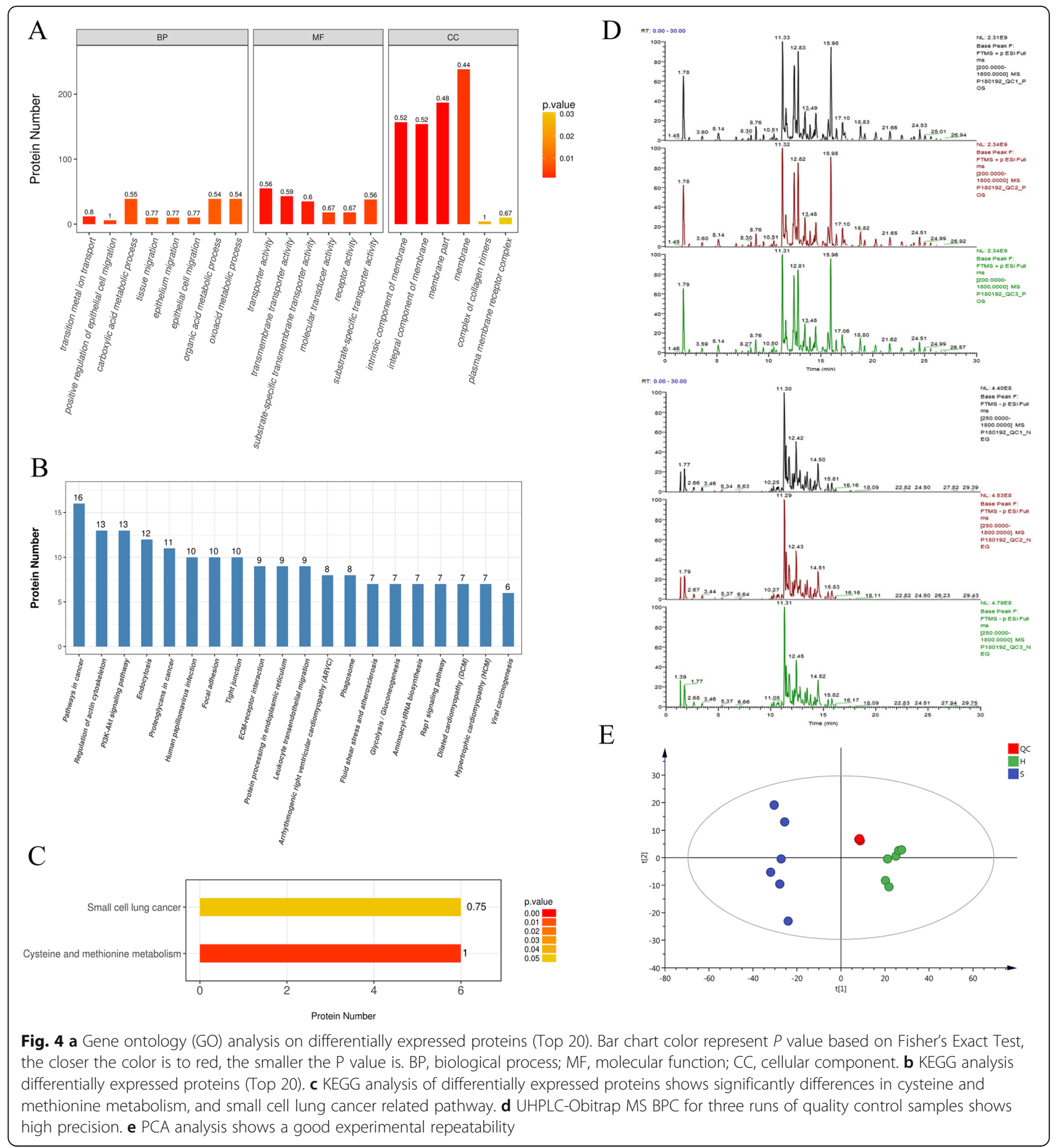

found lipoprotein lipase, a crucial node in the management of plasma lipid levels by promoting hydrolytic cleavage of the triglyceride core of lipoproteins, was rise significantly in SKOV-3 derived exosomes, this might be the reason for the plasma lipid species variation in malignant or borderline ovarian tumors, and benign pathology [28, 37].
Exosomes originate from the late endosomal compartment and transport their cargo extracellularly to communicate with other cells. It appears that exosome lipid composition is unique and does not reflect the composition of the plasma membrane [38]. Exosomes are enriched in lipids such as PCs and PEs and bioactive lipids involved in signaling such as SM, Cers, cholesterol, 

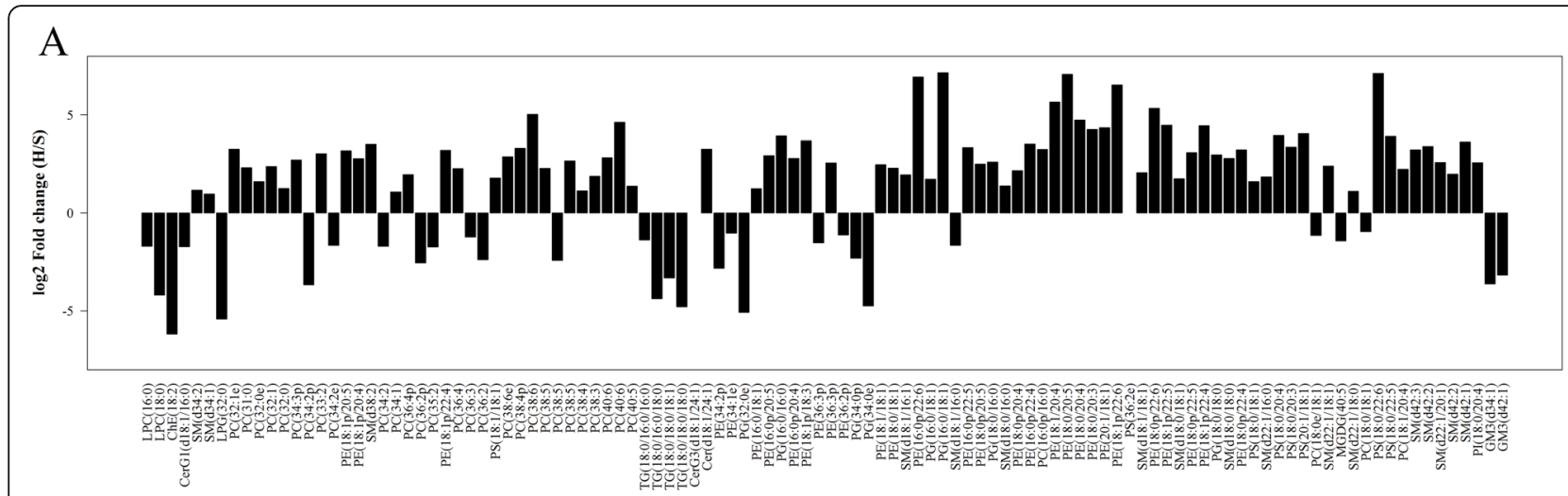

B
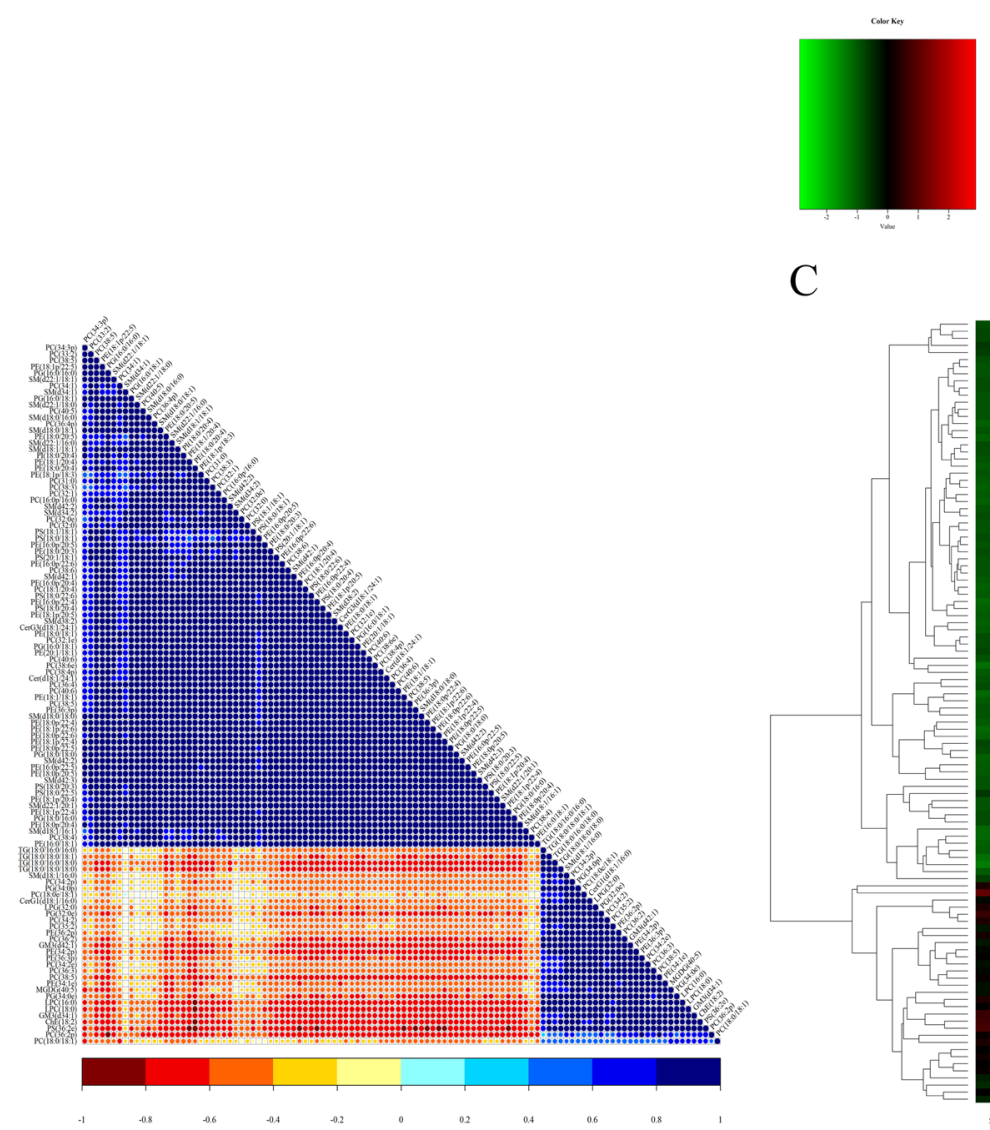

$\mathrm{C}$
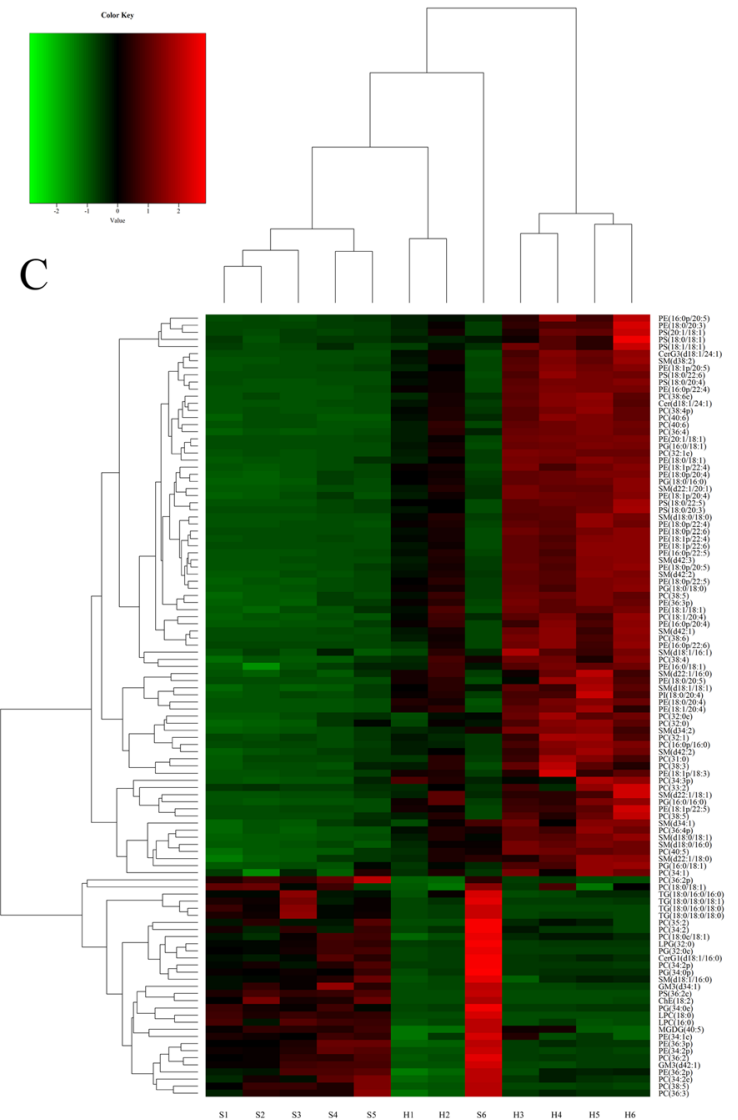

Fig. 5 a Analysis of lipid variation multiple with significant difference. $=\mathbf{b}$ Lipid correlation analysis of significant difference. $\mathbf{c}$ Cluster Analysis of lipidomic results

lysophosphatidylcholine, among others [39]. So far, there was no report about the lipidomics analysis of exosomes, either from ovarian cancer or in the context of ovarian surface epithelial cell line. We successfully identified a total of 1227 lipid species exosomal lipids from two ovarian cell lines by performing an LC-MS/MS workflow.

In terms of lipid classes, we noted that $\mathrm{ChE}$ and $\mathrm{ZyE}$ species were in general more abundant in exosomes from SKOV-3 than from HOSEPiC. It is interesting that resistin, a positive regulation of steroid hormone secretion protein, was only identified in exosomes derived from SKOV-3, since some proteins related with response to steroid hormone and steroid metabolic process were more abundant in exosomes from HOSEPiC. Aberrant regulation of cholesterol homeostasis has been associated with multiple types of cancer [40]. Moreover, numerous studies have shown increased levels of cholesterol in tumors as compared to normal tissue [40, 41], some suggesting cholesterol may accumulate in 
Table 1 Identified differential lipid species between two ovarian cell lines derived exosomes

\begin{tabular}{|c|c|c|c|c|c|c|}
\hline Lipidlon & CalMz & RT (min) & Fold Change & $P$-value & OPLS-DA VIP & QCRSD \\
\hline $\mathrm{LPC}(16: 0)+\mathrm{H}$ & 496.33977 & 3.3190213 & 3.2401429 & 0.0003273 & 1.1373 & 0.0297514 \\
\hline$L P C(18: 0)+H$ & 524.37107 & 4.7209243 & 18.269889 & 0.0003722 & 2.60482 & 0.0162352 \\
\hline $\operatorname{ChE}(18: 2)+\mathrm{NH} 4$ & 666.61836 & 22.834863 & 72.791038 & 0.0003399 & 2.89397 & 0.011065 \\
\hline $\operatorname{CerG1}(\mathrm{d} 18: 1 / 16: 0)+\mathrm{H}$ & 700.5722 & 11.699674 & 3.2940782 & 0.0306673 & 1.14636 & 0.0045913 \\
\hline $\mathrm{SM}(\mathrm{d} 34: 2)+\mathrm{H}$ & 701.5592 & 10.295418 & 0.4433831 & 0.0076993 & 1.16119 & 0.0658362 \\
\hline $\mathrm{SM}(\mathrm{d} 34: 1)+\mathrm{H}$ & 703.57485 & 11.59398 & 0.5114373 & 0.0367638 & 1.5197 & 0.0020378 \\
\hline $\operatorname{LPG}(32: 0)+H$ & 709.5378 & 12.101539 & 42.668799 & 0.0141787 & 2.26234 & 0.0588612 \\
\hline$P C(32: 1 e)+H$ & 718.57452 & 12.887364 & 0.1043478 & 0.0001296 & 2.05444 & 0.0049736 \\
\hline$P C(31: 0)+H$ & 720.55378 & 11.846352 & 0.2007092 & 0.0013034 & 1.24693 & 0.0262676 \\
\hline$P C(32: 0 e)+H$ & 720.59017 & 13.029801 & 0.3277517 & 0.0079895 & 1.90627 & 0.0053236 \\
\hline$P C(32: 1)+H$ & 732.55378 & 11.612277 & 0.1923281 & 0.0046353 & 2.73062 & 0.0462711 \\
\hline$P C(32: 0)+H$ & 734.56943 & 12.360385 & 0.4178622 & 0.0068592 & 3.52812 & 0.0127862 \\
\hline$P C(34: 3 p)+H$ & 740.55887 & 11.488 & 0.1531682 & 0.0021939 & 1.15239 & 0.0675083 \\
\hline$P C(34: 2 p)+H$ & 742.57452 & 12.158077 & 12.690591 & 0.0175789 & 2.15496 & 0.0040868 \\
\hline$P C(33: 2)+H$ & 744.55378 & 12.829097 & 0.1222581 & 0.0301204 & 1.49374 & 0.0676107 \\
\hline$P C(34: 2 e)+H$ & 744.59017 & 12.28901 & 3.1371582 & 0.0077942 & 1.67519 & 0.0831756 \\
\hline$P E(18: 1 p / 20: 5)+H$ & 748.52757 & 11.625209 & 0.1097354 & 0.0004896 & 1.32269 & 0.0171607 \\
\hline PE(18:1p/20:4)+H & 750.54322 & 12.501618 & 0.145539 & 0.000242 & 1.19719 & 0.0083309 \\
\hline $\mathrm{SM}(\mathrm{d} 38: 2)+\mathrm{H}$ & 757.6218 & 12.532221 & 0.087633 & 0.000192 & 1.0073 & 0.0213935 \\
\hline$P C(34: 2)+H$ & 758.56943 & 11.630869 & 3.2335929 & 0.0364593 & 5.7643 & 0.1027676 \\
\hline$P C(34: 1)+H$ & 760.58508 & 12.445472 & 0.4729024 & 0.0141368 & 5.97923 & 0.0810498 \\
\hline$P C(36: 4 p)+H$ & 766.57452 & 11.940753 & 0.2565588 & 0.0008954 & 1.12283 & 0.0060599 \\
\hline$P C(36: 2 p)+H$ & 770.60582 & 12.349255 & 5.8753359 & 0.0001111 & 1.20156 & 0.1285883 \\
\hline$P C(35: 2)+H$ & 772.58508 & 12.248583 & 3.3185929 & 0.0435064 & 1.71303 & 0.0021791 \\
\hline $\operatorname{PE}(18: 1 \mathrm{p} / 22: 4)+\mathrm{H}$ & 778.57452 & 13.294718 & 0.1085165 & 4.293E-05 & 1.13316 & 0.0007308 \\
\hline$P C(36: 4)+H$ & 782.56943 & 11.487673 & 0.2070776 & 0.0001643 & 2.85354 & 0.0116555 \\
\hline$P C(36: 3)+H$ & 784.58508 & 11.748421 & 2.3365561 & 0.0049429 & 3.18958 & 0.0241481 \\
\hline$P C(36: 2)+H$ & 786.60073 & 12.677741 & 5.2284223 & 0.0029346 & 7.57054 & 0.0179213 \\
\hline$P S(18: 1 / 18: 1)+H$ & 788.54361 & 11.642431 & 0.2881103 & 0.0102609 & 1.25586 & 0.0394853 \\
\hline$P C(38: 6 e)+H$ & 792.59017 & 11.988893 & 0.1371336 & 0.0005692 & 1.11168 & 0.0054911 \\
\hline$P C(38: 4 p)+H$ & 794.60582 & 12.934363 & 0.1005617 & 7.065E-05 & 1.04556 & 0.0036017 \\
\hline$P C(38: 6)+H$ & 806.56943 & 11.187251 & 0.0307172 & 0.000384 & 1.03144 & 0.0063008 \\
\hline$P C(38: 5)+H$ & 808.58508 & 11.810332 & 0.2048139 & $2.768 \mathrm{E}-05$ & 1.17442 & 0.2107591 \\
\hline$P C(38: 5)+H$ & 808.58508 & 12.672307 & 5.3756449 & 0.0003799 & 2.10979 & 0.0183503 \\
\hline$P C(38: 5)+H$ & 808.58508 & 11.552074 & 0.1578107 & 0.0010544 & 2.61177 & 0.0658505 \\
\hline$P C(38: 4)+H$ & 810.60073 & 12.488833 & 0.4547764 & 0.0017399 & 2.12696 & 0.001785 \\
\hline$P C(38: 3)+H$ & 812.61638 & 12.668413 & 0.272076 & 0.0008442 & 1.10512 & 0.028863 \\
\hline$P C(40: 6)+H$ & 834.60073 & 11.597658 & 0.141325 & 0.0001152 & 1.03595 & 0.0098316 \\
\hline$P C(40: 6)+H$ & 834.60073 & 12.20053 & 0.0405773 & 5.149E-05 & 1.72933 & 0.0220091 \\
\hline$P C(40: 5)+H$ & 836.61638 & 12.501089 & 0.3850075 & 0.0014969 & 1.6471 & 0.0468449 \\
\hline $\mathrm{TG}(18: 0 / 16: 0 / 16: 0)+\mathrm{NH} 4$ & 852.80147 & 23.939109 & 2.5892204 & 0.0391508 & 1.59551 & 0.0019084 \\
\hline $\mathrm{TG}(18: 0 / 16: 0 / 18: 0)+\mathrm{NH} 4$ & 880.83277 & 24.519245 & 20.899098 & 0.0029053 & 3.16115 & 0.0048875 \\
\hline $\mathrm{TG}(18: 0 / 18: 0 / 18: 1)+\mathrm{NH} 4$ & 906.84842 & 24.538863 & 10.011565 & 0.0111865 & 1.50329 & 0.012747 \\
\hline $\mathrm{TG}(18: 0 / 18: 0 / 18: 0)+\mathrm{NH} 4$ & 908.86407 & 25.00585 & 27.739567 & 0.0034531 & 2.08332 & 0.046467 \\
\hline
\end{tabular}


Table 1 Identified differential lipid species between two ovarian cell lines derived exosomes (Continued)

\begin{tabular}{|c|c|c|c|c|c|c|}
\hline Lipidlon & CalMz & $\mathrm{RT}$ (min) & Fold Change & $P$-value & OPLS-DA VIP & QCRSD \\
\hline CerG3(d18:1/24:1)+H & 1134.7874 & 14.091305 & 0 & 0.0001224 & 1.07113 & 0.0066018 \\
\hline Cer(d18:1/24:1) + HCOO & 692.61985 & 16.175473 & 0.103872 & 0.0001471 & 1.25519 & 0.0215203 \\
\hline$P E(34: 2 p)-H$ & 698.51302 & 12.449142 & 7.0769491 & 0.0006763 & 3.93889 & 0.0324108 \\
\hline PE(34:1e)-H & 702.54432 & 13.438345 & 2.0385687 & 0.0113353 & 1.156 & 0.0088682 \\
\hline PG(32:0e)-H & 707.52325 & 12.091773 & 33.793704 & 0.0061178 & 6.58985 & 0.0156174 \\
\hline PE(16:0/18:1)-H & 716.52358 & 12.720163 & 0.4202182 & 0.0004424 & 1.83386 & 0.0108465 \\
\hline$P E(16: 0 p / 20: 5)-H$ & 720.49737 & 11.583383 & 0.1314003 & 0.0051701 & 1.44299 & 0.0107055 \\
\hline$P G(16: 0 / 16: 0)-H$ & 721.50251 & 11.473539 & 0.0657456 & $1.681 \mathrm{E}-05$ & 7.95788 & 0.0536726 \\
\hline PE(16:0p/20:4)-H & 722.51302 & 12.248596 & 0.1447987 & $2.026 \mathrm{E}-05$ & 4.13162 & 0.073243 \\
\hline$P E(18: 1 p / 18: 3)-H$ & 722.51302 & 11.479 & 0.0774059 & 0.0007414 & 2.93232 & 0.0263587 \\
\hline$P E(36: 3 p)-H$ & 724.52867 & 12.689641 & 2.8785532 & 0.0012986 & 1.82325 & 0.0338385 \\
\hline$P E(36: 3 p)-H$ & 724.52867 & 12.527277 & 0.1696422 & $1.244 \mathrm{E}-05$ & 1.10348 & 0.0758919 \\
\hline$P E(36: 2 p)-H$ & 726.54432 & 13.506758 & 2.1755145 & 0.0056018 & 3.72929 & 0.0298701 \\
\hline PG(34:0p)-H & 733.5389 & 12.13369 & 4.956339 & 0.0246676 & 2.58981 & 0.0648588 \\
\hline PG(34:0e)-H & 735.55455 & 13.058572 & 26.79393 & 0.0073044 & 1.85088 & 0.0811271 \\
\hline PE(18:1/18:1)-H & 742.53923 & 12.800264 & 0.1802797 & 2.189E-05 & 4.40304 & 0.107758 \\
\hline $\operatorname{PE}(18: 0 / 18: 1)-H$ & 744.55488 & 13.783132 & 0.2032096 & 0.0005934 & 2.90082 & 0.0055799 \\
\hline $\mathrm{SM}(\mathrm{d} 18: 1 / 16: 1)+\mathrm{HCOO}$ & 745.55013 & 10.268659 & 0.2587852 & 0.003933 & 1.11216 & 0.0391053 \\
\hline$P E(16: 0 p / 22: 6)-H$ & 746.51302 & 11.933663 & 0.0081673 & 0.0009601 & 2.06975 & 0.037648 \\
\hline$P G(16: 0 / 18: 1)-H$ & 747.51816 & 11.589231 & 0.2997752 & 0.0061899 & 1.95396 & 0.0031406 \\
\hline$P G(16: 0 / 18: 1)-H$ & 747.51816 & 12.082 & 0.0070412 & 0.0001049 & 1.70948 & 0.0101288 \\
\hline $\mathrm{SM}(\mathrm{d} 18: 1 / 16: 0)+\mathrm{HCOO}$ & 747.56578 & 11.143139 & 3.1337131 & 0.0163085 & 1.20354 & 0.1452831 \\
\hline$P E(16: 0 p / 22: 5)-H$ & 748.52867 & 12.289308 & 0.0987534 & $8.502 \mathrm{E}-05$ & 3.64684 & 0.0068211 \\
\hline$P E(18: 0 p / 20: 5)-H$ & 748.52867 & 12.567227 & 0.1766982 & 0.0002361 & 1.83825 & 0.009736 \\
\hline$P G(18: 0 / 16: 0)-H$ & 749.53381 & 12.425961 & 0.1646077 & $5.421 \mathrm{E}-05$ & 2.56412 & 0.0199873 \\
\hline $\mathrm{SM}(\mathrm{d} 18: 0 / 16: 0)+\mathrm{HCOO}$ & 749.58143 & 11.7146 & 0.3821158 & 0.0016634 & 1.98624 & 0.0581853 \\
\hline PE(18:0p/20:4)-H & 750.54432 & 13.279505 & 0.2216461 & $5.222 \mathrm{E}-05$ & 3.07046 & 0.0127945 \\
\hline PE(16:0p/22:4)-H & 750.54432 & 12.97263 & 0.0866529 & $3.018 \mathrm{E}-05$ & 1.93611 & 0.0087864 \\
\hline$P C(16: 0 p / 16: 0)+\mathrm{HCOO}$ & 762.56545 & 12.873873 & 0.1047239 & 0.0025272 & 1.16224 & 0.0074952 \\
\hline PE(18:1/20:4)-H & 764.52358 & 11.833072 & 0.0198255 & 2.089E-05 & 2.0106 & 0.0174142 \\
\hline PE(18:0/20:5)-H & 764.52358 & 12.138 & 0.0074497 & 0.0003435 & 1.20561 & 0.0241654 \\
\hline PE(18:0/20:4)-H & 766.53923 & 12.75693 & 0.0375343 & 4.79E-06 & 3.30905 & 0.1177161 \\
\hline PE(18:0/20:3)-H & 768.55488 & 13.193352 & 0.0522966 & 0.003736 & 1.16198 & 0.0061066 \\
\hline PE(20:1/18:1)-H & 770.57053 & 13.784833 & 0.0493772 & 0.0002845 & 1.56243 & 0.0107648 \\
\hline$P E(18: 1 p / 22: 6)-H$ & 772.52867 & 12.002327 & 0.010826 & 0.0002546 & 1.51339 & 0.0270652 \\
\hline$P S(36: 2 e)-H$ & 772.5498 & 11.450658 & \#DIV/O! & $7.631 \mathrm{E}-05$ & 1.33306 & 0.0013688 \\
\hline $\mathrm{SM}(\mathrm{d} 18: 1 / 18: 1)+\mathrm{HCOO}$ & 773.58143 & 11.463026 & 0.2381133 & 0.0003138 & 1.47317 & 0.0137748 \\
\hline$P E(18: 0 p / 22: 6)-H$ & 774.54432 & 12.944895 & 0.0248033 & 7.927E-05 & 1.9671 & 0.0044874 \\
\hline$P E(18: 1 p / 22: 5)-H$ & 774.54432 & 12.319588 & 0.0451147 & 0.0005202 & 1.26561 & 0.0308905 \\
\hline $\mathrm{SM}(\mathrm{d} 18: 0 / 18: 1)+\mathrm{HCOO}$ & 775.59708 & 12.38504 & 0.2961012 & 0.0003765 & 2.84705 & 0.0099288 \\
\hline PE(18:0p/22:5)-H & 776.55997 & 13.285239 & 0.1177648 & $2.278 \mathrm{E}-05$ & 1.95952 & 0.0080996 \\
\hline$P E(18: 1 p / 22: 4)-H$ & 776.55997 & 13.012059 & 0.0459673 & $6.588 \mathrm{E}-05$ & 1.21688 & 0.0024014 \\
\hline$P G(18: 0 / 18: 0)-H$ & 777.56511 & 13.412865 & 0.1266703 & 4.927E-05 & 1.43803 & 0.0305797 \\
\hline $\mathrm{SM}(\mathrm{d} 18: 0 / 18: 0)+\mathrm{HCOO}$ & 777.61273 & 12.769534 & 0.1442123 & 4.697E-05 & 1.23292 & 0.0171988 \\
\hline
\end{tabular}


Table 1 Identified differential lipid species between two ovarian cell lines derived exosomes (Continued)

\begin{tabular}{|c|c|c|c|c|c|c|}
\hline Lipidlon & CalMz & $\mathrm{RT}$ (min) & Fold Change & $P$-value & OPLS-DA VIP & QCRSD \\
\hline $\mathrm{PE}(18: 0 \mathrm{p} / 22: 4)-\mathrm{H}$ & 778.57562 & 14.047477 & 0.107071 & 2.975E-05 & 1.1974 & 0.0061423 \\
\hline $\operatorname{PS}(18: 0 / 18: 1)-H$ & 788.54471 & 12.473056 & 0.3286841 & 0.0297073 & 2.66766 & 0.016332 \\
\hline $\mathrm{SM}(\mathrm{d} 22: 1 / 16: 0)+\mathrm{HCOO}$ & 803.62838 & 13.458944 & 0.2784275 & 0.0002187 & 1.11001 & 0.0696966 \\
\hline PS(18:0/20:4)-H & 810.52906 & 11.58011 & 0.0645448 & 0.0001105 & 1.45732 & 0.0093627 \\
\hline PS(18:0/20:3)-H & 812.54471 & 11.97813 & 0.0967219 & 0.0004739 & 1.80055 & 0.0917789 \\
\hline $\operatorname{PS}(20: 1 / 18: 1)-H$ & 814.56036 & 12.487242 & 0.0604681 & 0.002872 & 1.35476 & 0.0169701 \\
\hline $\mathrm{PC}(18: 0 \mathrm{e} / 18: 1)+\mathrm{HCOO}$ & 818.62805 & 14.214201 & 2.2124072 & 0.0456916 & 1.2273 & 0.0203368 \\
\hline $\mathrm{SM}(\mathrm{d} 22: 1 / 18: 1)+\mathrm{HCOO}$ & 829.64403 & 13.588027 & 0.1901319 & 0.002038 & 1.56036 & 0.0645059 \\
\hline MGDG(40:5)-H & 831.59917 & 12.658 & 2.6826723 & 0.0060226 & 3.97242 & 0.0061761 \\
\hline $\mathrm{SM}(\mathrm{d} 22: 1 / 18: 0)+\mathrm{HCOO}$ & 831.65968 & 14.596852 & 0.4635037 & 0.007412 & 1.82634 & 0.0147283 \\
\hline $\mathrm{PC}(18: 0 / 18: 1)+\mathrm{HCOO}$ & 832.60731 & 12.864 & 1.924755 & 0.0336785 & 1.82967 & 0.0768031 \\
\hline PS(18:0/22:6)-H & 834.52906 & 11.311759 & 0.0071894 & 0.0001123 & 1.4428 & 0.00347 \\
\hline PS(18:0/22:5)-H & 836.54471 & 11.595335 & 0.0667759 & 0.0001863 & 1.29217 & 0.0258396 \\
\hline$P C(18: 1 / 20: 4)+\mathrm{HCOO}$ & 852.57601 & 11.52204 & 0.2125022 & $5.243 E-05$ & 1.16355 & 0.0111386 \\
\hline $\mathrm{SM}(\mathrm{d} 42: 3)+\mathrm{HCOO}$ & 855.65968 & 13.525602 & 0.1063234 & 0.0001879 & 2.9138 & 0.0199491 \\
\hline $\mathrm{SM}(\mathrm{d} 42: 2)+\mathrm{HCOO}$ & 857.67533 & 13.545112 & 0.0942641 & $9.483 \mathrm{E}-05$ & 1.18221 & 0.0006172 \\
\hline $\mathrm{SM}(\mathrm{d} 22: 1 / 20: 1)+\mathrm{HCOO}$ & 857.67533 & 14.526616 & 0.167393 & 0.000104 & 5.06469 & 0.0136233 \\
\hline $\mathrm{SM}(\mathrm{d} 42: 2)+\mathrm{HCOO}$ & 857.67533 & 14.727306 & 0.252808 & 0.001211 & 1.75892 & 0.023403 \\
\hline $\mathrm{SM}(\mathrm{d} 42: 1)+\mathrm{HCOO}$ & 859.69098 & 14.966437 & 0.0806861 & 0.0003376 & 1.01072 & 0.0182043 \\
\hline PI(18:0/20:4)-H & 885.54986 & 11.369021 & 0.1675608 & 0.0003305 & 2.32953 & 0.0672784 \\
\hline GM3(d34:1)-H & 1151.7059 & 9.9060133 & 12.292786 & 0.001588 & 1.16125 & 0.126017 \\
\hline GM3(d42:1)-H & 1263.8311 & 13.772293 & 8.9902052 & 0.0008371 & 1.08214 & 0.0259905 \\
\hline
\end{tabular}

tumor tissue [42, 43]. As we observed, similarly to tumor tissue, both cholesterol and its precursor zymosterol were both accumulate in tumor derived exosomes. It is not clear why this is the case, it is possible that the exosomal steroid concentration is cell type dependent and/ or depends on the transfer information packaged by the exosome-secreting cells [14]. Unfortunately, no similar results were found in EOC patient's serum or plasma samples [37]. This may be due to the complicated sources of lipid composition in serum or plasma, of which only a minority of lipid metabolic changes due to ovarian cancer, therefore focuses on the exosomes can show the advantages: the tumor cells secrete exosomes exhaustedly, most exosomes in peripheral blood are tumor derived, and can better reflect the lipid metabolic disorder of tumor, thus supporting the early diagnosis of ovarian cancer.

Lysophosphatidic acid has been proposed to be involved in various cancers through different pathogenesis [44]. For example, LPE causes migration and the invasion of ovarian cancer cells [45]; LPS suppress $\mathrm{T}$ lymphocyte proliferation [46], and stimulates the migration of colorectal cancer cells and glioma cells [47, 48]. In our study, we found that exosomes from HOSEPiC were more abundant in PS, PI, PE, PG, while exosomes from SKOV-3 were more abundant in LPI, LPS, LPG, LPC, suggesting that the exosomal lipids play an important role in the progress of tumor invasion and metastasis. To our knowledge, Urban et al. [49] have observed the similar results. Their lipidomic studies presented on the urinary exosome lipid repertoire in control and renal cell carcinoma patient, and showed lysophospholipids were the largest differences lipid classes.

In terms of lipid species, we successfully identified 1212 species in exosomes from HOSEPiC and 1202 species in exosomes from SKOV3. More details were list in Additional file 3: Table S3 for the species number relationship. In total, 110 lipid species were screened out with significant differences between each group. The highest significance were PG(34:1)-H and ChE(18:2) + NH4. Furthermore, some lipid species showed species specificity, such as CerG3(d42:2) + H were only identified in exosomes from HOSEPiC, PS(36:2e)-H were only identified in exosomes from SKOV3, indicating that the potential use of exosomal lipid species as cancer biomarkers. 5 lipid species also reported by $\mathrm{Li}$ and his group in a lipidomic study of plasma from 70 EOC patients [28].

In conclusion, this study shows that exosomal lipids and protein are promising cancer biomarkers. Several 
lipid species and proteins significantly differ in SKOV-3 derived exosomes compared to those from HOSEPiC. Further experiments will have to be performed in clinical specimens to validate these results. Thus demonstrating their diagnostic potential, additional specimens will have to be included: For example, exosomes derived from tissues and peripheral blood of benign ovarian tumor patients and borderline ovarian tumor patients, to investigate the specificity and use of these biomarkers in early diagnosis, and patients at different stages of disease to investigate if they can be used to indicate the process of malignant tumor.

\section{Supplementary information}

Supplementary information accompanies this paper at https://doi.org/10 1186/s13048-020-0609-y

Additional file 1: Table S1. Identified proteins from two ovarian cell lines derived exosomes.

Additional file 2: Table S2. consistent presence / absence expression protein profile.

Additional file 3: Table S3. Identified lipid species from two ovarian cell lines derived exosomes.

Additional file 4: Table S4. Identified lipid classes from two ovarian cell lines derived exosomes.

\section{Abbreviation}

Cer: Ceramides; CerG: Simple Glc series; ChE: Cholesterol Ester; EV: Extracellular vesicles; GM: Gangliosides; LPC: Lysophosphatidylcholine; LPC: Lysophosphatidylcholine; LPG: Lysophosphatidylglycerol; LPI: Lysophosphatidylinositol; LPS: Lysophosphatidylserine; MGDG: Monogalactosyldiacylglycerol; PC: Phosphatidylcholine; PE: Phosphatidylethanolamine; PG: Phosphatidylglycerol; PI: Phosphatidylinositol; PS: Phosphatidylserine; SM: Sphingomyelin; TG: Triglyceride; ZyE: Zymosterol

\section{Acknowledgments}

We thank Shanghai Applied protein technology for the mass spectrometry identification.

\section{Authors' contributions}

All authors read and approved the final manuscript.

\section{Funding}

This study was supported by grants from the National Natural Science Foundation of China (81302242), Jilin Province Development and Reform Commission (2016C046-2), and the Education Department of Jilin Province (JJKH20170840KJ)

\section{Availability of data and materials}

The datasets used and/or analyzed during the current study are available from the corresponding author on reasonable request.

\section{Ethics approval and consent to participate}

Not applicable.

\section{Consent for publication}

Not applicable.

\section{Competing interests}

The authors declare that they have no competing interests.

\section{Author details}

The Second Hospital of Jilin University, 218 Ziqiang Street, Changchun 130000, China. ${ }^{2}$ Department of Human Genetics, Emory University School of Medicine, 615 Michael Street, Atlanta, GA 30322, USA.

Received: 4 September 2019 Accepted: 5 January 2020

Published online: 22 January 2020

\section{References}

1. Tkach $M$. Thery $C$ communication by extracellular vesicles: where we are and where we need to go. Cell. 2016;164(6):1226-32.

2. Zappulli V, Friis KP, Fitzpatrick Z, et al. Extracellular vesicles and intercellular communication within the nervous system. J Clin Investig. 2016;126(4): 1198-207.

3. Ciardiello C, Cavallini L, Spinelli C, et al. Focus on Extracellular Vesicles: New Frontiers of Cell-to-Cell Communication in Cancer. Int J Mol Sci. 2016;17(2): 175.

4. Lauwers E, Wang YC, Gallardo R, et al. Hsp90 Mediates Membrane Deformation and Exosome Release. Mol Cell. 2018;71(5):689-702 e9.

5. Shurtleff MJ, Temoche-Diaz MM, Karfilis KV, et al. Y-box protein 1 is required to sort microRNAs into exosomes in cells and in a cell-free reaction. Elife. 2016:5:e19276.

6. Colombo M, Raposo G, Thery C. Biogenesis, Secretion, and Intercellular Interactions of Exosomes and Other Extracellular Vesicles. Annu Rev Cell Deve Biol. 2014;30:255-89.

7. Raiborg C. Stenmark H the ESCRT machinery in endosomal sorting of ubiquitylated membrane proteins. Nat. 2009;458(7237):445-52.

8. Hurley JH, Odorizzi G. Get on the exosome bus with ALIX. Nat Cell Biol. 2012;14(7):654-5.

9. Szajnik M, Derbis M, Lach M, et al. Exosomes in Plasma of Patients with Ovarian Carcinoma: Potential Biomarkers of Tumor Progression and Response to Therapy. Gynecology Obstet (Sunnyvale), 2013;Suppl 4(3-3.

10. Escrevente $C$, Keller $S$, Altevogt $P$, et al. Interaction and uptake of exosomes by ovarian cancer cells. BMC Cancer. 2011;11:108.

11. Dorayappan KDP, Wallbillich JJ, Cohn DE, et al. The biological significance and clinical applications of exosomes in ovarian cancer. Gynecol Oncol. 2016;142(1):199-205

12. Cheng L, Wu SY, Zhang K, et al. A comprehensive overview of exosomes in ovarian cancer: emerging biomarkers and therapeutic strategies. J Ovarian Res. 2017;10(1):73

13. Yeung CLA, Co NN, Tsuruga T, et al. Exosomal transfer of stroma-derived miR21 confers paclitaxel resistance in ovarian cancer cells through targeting APAF1. Nat Commun. 2016;7:11150.

14. Skotland T, Ekroos K, Kauhanen D, et al. Molecular lipid species in urinary exosomes as potential prostate cancer biomarkers. Eur JCancer. 2017;70: $122-32$

15. Yang JP, Wei F, Schafer C, et al. Detection of Tumor Cell-Specific mRNA and Protein in Exosome-Like Microvesicles from Blood and Saliva. PLoS One. 2014;9(11):e110641.

16. Riancho J, Vazquez-Hiquera JL, Pozueta A, et al. MicroRNA profile in patients with Alzheimer's disease: analysis of miR-9-5p and miR-598 in raw and exosome enriched cerebrospinal fluid samples. J Alzheimers Dis. 2017:57(2): 483-91.

17. Paredes PT, Gutzeit C, Johansson S, et al. Differences in exosome populations in human breast milk in relation to allergic sensitization and lifestyle. Allergy. 2014;69(4):463-71.

18. Valenti G, Vitale SG, Tropea A, et al. Tumor markers of uterine cervical cancer: a new scenario to guide surgical practice? Updat Surg. 2017;69(4): 441-9.

19. Webb PM, Jordan SJ. Epidemiology of epithelial ovarian cancer. Best Practice \& Research Clinical. Obstet Gynaecol. 2017:41:3-14.

20. Szajnik M, Czystowska-Kuzmicz M, Elishaev E, et al. Biological markers of prognosis, response to therapy and outcome in ovarian carcinoma. Expert Rev Mol Diagn. 2016;16(8):811-26.

21. Vitale SG, Capriglione S, Zito G, et al. Management of endometrial, ovarian and cervical cancer in the elderly: current approach to a challenging condition. Arch Gynecol Obstet. 2019;299(2):299-315.

22. Schuurman MS, Kruitwagen RFPM, Portielje JEA, et al. Treatment and outcome of elderly patients with advanced stage ovarian cancer: a nationwide analysis. Gynecol Oncol. 2018;149(2):270-4. 
23. Thery C, Amigorena S, Raposo G, et al. Isolation and characterization of exosomes from cell culture supernatants and biological fluids. Curr Protoc Cell Biol. 2006; Chapter 3(Unit 3.22-Unit 23.22.

24. Cox J, Mann M. MaxQuant enables high peptide identification rates, individualized p.p.b.-range mass accuracies and proteome-wide protein quantification. Nat Biotechnol. 2008;26(12):1367-72

25. Zhou YY, Chen LP, Zhang Y, et al. Integrated transcriptomic analysis reveals hub genes involved in diagnosis and prognosis of pancreatic cancer. Mol Med. 2019;25(1):47

26. Zeng XT, Liu XP, Liu TZ, et al. The clinical significance of COL5A2 in patients with bladder cancer: A retrospective analysis of bladder cancer gene expression data. Med. 2018;97(10):e0091.

27. Moriya $Y$, Itoh M, Okuda S, et al. KAAS: an automatic genome annotation and pathway reconstruction server. Nucleic Acids Res. 2007;35:W182-5.

28. Li JN, Xie HY, Li A, et al. Distinct plasma lipids profiles of recurrent ovarian cancer by liquid chromatography-mass spectrometry. Oncotarget. 2017;8(29):46834-45.

29. Melo SA, Luecke LB, Kahlert C, et al. Glypican-1 identifies cancer exosomes and detects early pancreatic cancer. Nat. 2015;523(7559):177-U182.

30. Wang L, Li Y, Guan X, et al. Exosomal double-stranded DNA as a biomarker for the diagnosis and preoperative assessment of pheochromocytoma and paraganglioma. Mol Cancer. 2018;17(1):128.

31. Otero-Ortega L, Laso-Garcia F, Gomez-De Frutos M, et al. Role of Exosomes as a treatment and potential biomarker for stroke. Transl Stroke Res. 2019; 10(3):241-9.

32. Sinha $A$, Ignatchenko $V$, lgnatchenko $A$, et al. In-depth proteomic analyses of ovarian cancer cell line exosomes reveals differential enrichment of functional categories compared to the. $\mathrm{NCl} 60$ proteome. Biochem Biophys Res Commun. 2014;445(4):694-701.

33. Liang $B$, Peng $P$, Chen $S$, et al. Characterization and proteomic analysis of ovarian cancer-derived exosomes. J Proteomics. 2013;80:171-82.

34. Zhang $W$, Ou XX, Wu XH. Proteomics profiling of plasma exosomes in epithelial ovarian cancer: a potential role in the coagulation cascade, diagnosis and prognosis. Int J Oncol. 2019;54(5):1719-33.

35. Iraci N, Gaude E, Leonardi T, et al. Extracellular vesicles are independent metabolic units with asparaginase activity. Nat Chem Biol. 2017;13(9):951-5.

36. Yi $H$, Zheng $X Q$, Song JR, et al. Exosomes mediated pentose phosphate pathway in ovarian cancer metastasis: a proteomics analysis. Int J Clin Exp Pathol. 2015;8(12):15719-28.

37. Niemi RJ, Braicu El, Kulbe H, et al. Ovarian tumours of different histologic type and clinical stage induce similar changes in lipid metabolism. Br J Cancer. 2018;119(7):847-54.

38. Dang VD, Jella KK, Ragheb RRT, et al. Lipidomic and proteomic analysis of exosomes from mouse cortical collecting duct cells. FASEB J. 2017;31(12): 5399-408.

39. Laulagnier K, Motta C, Hamdi S, et al. Mast cell- and dendritic cell-derived exosomes display a specific lipid composition and an unusual membrane organization. Biochem J. 2004;380:161-71.

40. Smith $\mathrm{B}$. Land $\mathrm{H}$ anticancer activity of the cholesterol exporter ABCA1 gene. Cell Rep. 2012;2(3):580-90

41. Yoshioka Y, Sasaki J, Yamamoto M, et al. Quantitation by H-1-NMR of dolichol, cholesterol and choline-containing lipids in extracts of normal and phathological thyroid tissue. NMR Biomed. 2000;13(7):377-83.

42. Graziani S R, Igreja F, A F, Hegg R, et al. Uptake of a cholesterol-rich emulsion by breast cancer. Gynecol Oncol, 2002;85(3): 493-497.

43. Ades A, Carvalho JP, Graziani SR, et al. Uptake of a cholesterol-rich emulsion by neoplastic ovarian tissues. Gynecol Oncol. 2001;82(1):84-7.

44. Emoto S, Kurano M, Kano K, et al. Analysis of glycero-lysophospholipids in gastric cancerous ascites. J Lipid Res. 2017;58(4):763-71.

45. Park KS, Lee HY, Lee SY, et al. Lysophosphatidylethanolamine stimulates chemotactic migration and cellular invasion in SK-OV3 human ovarian cancer cells: involvement of pertussis toxin-sensitive G-protein coupled receptor. FEBS Lett. 2007:581(23):4411-6.

46. Uwamizu A, Inoue A, Suzuki K, et al. Lysophosphatidylserine analogues differentially activate three LysoPS receptors. J Biochem. 2015;157(3):151-60.

47. Iida Y, Tsuno NH, Kishikawa J, et al. Lysophosphatidylserine stimulates chemotactic migration of colorectal Cancer cells through GPR34 and PI3K Akt pathway. Anticancer Res. 2014;34(10):5465-72.

48. Lee SY, Lee HY, Kim SD, et al. Lysophosphatidylserine stimulates chemotactic migration in U87 human glioma cells. Biochem Biophys Res Commun. 2008;374(1):147-51.
49. Del Boccio P, Raimondo F, Pieragostino D, et al. A hyphenated microLC-QTOF-MS platform for exosomal lipidomics investigations: application to RCC urinary exosomes. Electrophor. 2012;33(4):689-96.

\section{Publisher's Note}

Springer Nature remains neutral with regard to jurisdictional claims in published maps and institutional affiliations.
Ready to submit your research? Choose BMC and benefit from:

- fast, convenient online submission

- thorough peer review by experienced researchers in your field

- rapid publication on acceptance

- support for research data, including large and complex data types

- gold Open Access which fosters wider collaboration and increased citations

- maximum visibility for your research: over $100 \mathrm{M}$ website views per year

At BMC, research is always in progress.

Learn more biomedcentral.com/submissions 